\title{
EDITORIAL STATEMENT
}

Half life of $\mathbf{C}^{14}$. In accordance with the decision of the Fifth Radiocarbon Dating Conference, Cambridge, 1962, all dates published in this volume (as in Volume 6) are based on the Libby value, $5570 \pm 30 \mathrm{yr}$, for the half life. The decision of the Conference gains time for further study, not only of the half life, but of other uncertainties, before republication of all dates is agreed upon. As stated in Professor Harry Godwin's letter to Nature (v. 195, no. 4845 , p. 984, September 8,1962 ), the mean of three new determinations of the half life, $5730 \pm 40 \mathrm{yr}$, is regarded as the best value now obtainable. Conversion of published dates to this hasis is accomplished by multiplying them by 1.03 .

A.D./B.C. dates. As agreed at the Cambridge Conference in 1962, A.D. 1950 is accepted as the standard year of reference for all dates, whether B.P. or in the A.D./B.C. system. 